\title{
Emergency Department waiting times in a tertiary children's hospital in Israel: a retrospective cohort study
}

\author{
Oren Feldman ${ }^{1}$, Raviv Allon², Ronit Leiba ${ }^{3}$ and Itai Shavit ${ }^{1,4^{*}}$
}

\begin{abstract}
Background: The purpose of this study was to assess ethnic differences in Emergency Department (ED) waiting times between Jewish and Arab children in a tertiary childrens' hospital in Israel.

Methods: This was a retrospective cohort study of all children who were admitted to the pediatric ED of the largest hospital in northern Israel, between January 2011 and December 2015. Univariate and multivariate analyses were used to assess the strength of association between ethnicity category and waiting time. The following were tested as possible confounders: triage category, age, gender, time of arrival category. The effect of nurse-patient ethnic concordance was assessed.

Results: Full data were available in 82,883 patients, 55,497 (67.0\%) Jews and 27,386 (33.0\%) Arabs. Jews and Arabs had a similar median waiting time of 38 min (interquartile range [IQR] 22-63 and IQR 21-61, respectively). Ethnicity was not associated with a change in waiting time $(p=0.36)$. Factors that most influenced shorter waiting time were triage category 1 (change in waiting time: $-25.5 \%$; 95\% confidence interval [Cl]: -29.3 to -21.7 ), or triage category 2 (change in waiting-time: $-21.8 \% ; 95 \% \mathrm{Cl}:-23.7$ to -20.05$)$. Factors that most influenced longer waiting time were patient arrival during the morning shift period (change in waiting time: $5.45 \%$; $95 \% \mathrm{Cl}: 4.59$ to 6.31 ), or during the evening shift period (change in waiting time: 4.46\%; 95\% Cl: 3.62 to 5.29). Ethnic discordance between triage nurses and patients did not yield longer waiting times.
\end{abstract}

Conclusion: In this large pediatric cohort, ethnic differences in ED waiting time were not found.

Keywords: Emergency, Child, Waiting time, Ethnicity

\section{Background}

Emergency Department (ED) waiting time, the period of time between ED registration and time of initial physician assessment, is an accepted measure for the quality of inhospital emergency care. Longer waiting times not only causing patients' dissatisfaction with the care received but may also result in patient deterioration and suffering and in delays in diagnosis and treatment $[1,2]$. Previous studies revealed that ethnicity could independently be associated with ED waiting times. These U.S. studies reported that Hispanic children and non-Hispanic black children

\footnotetext{
* Correspondence: i_shavit@rambam.health.gov.il

${ }^{1}$ Pediatric Emergency Department, Rambam Health Care Campus, Haifa, Israel

${ }^{4}$ POB 274, 3080500 Haifa, Israel

Full list of author information is available at the end of the article
}

had longer waiting times than non-Hispanic white children $[3,4]$.

The population of Israel includes two ethnic groups; Jews (majority group) and Arabs (minority group) [5] To date, there have been no studies that have evaluated possible differences in waiting time between Jews and Arabs in this bi-ethnic state.

The aim of this study was to determine if there are ethnic differences in ED waiting time between Jewish and Arab children in a tertiary children's hospital in Israel.

\section{Methods}

\section{Study design}

A retrospective single-center cohort study was conducted over a period of 5 years. Patients who were admitted to 
the pediatric ED between January 1, 2011, and December 31,2015 , were included in the study.

\section{Setting}

Located in the city of Haifa, Rambam Health Care Campus (RHCC) is the only tertiary hospital in the north of the country, and serves as a referral center for 12 district hospitals. RHCC is a public hospital that serves a population of more than two million residents of northern Israel; 600,000 are children, two-thirds are Jews, onethird are Arabs [6].

\section{Triage}

The ED nursing staff in this hospital uses the pediatric Canadian Triage Acuity Scale to triage patients [7]. The pediatric Canadian Triage Acuity Scale is a triage method that has been widely used in Canada and other countries as of 2001 [8-10]. Using this method, patients are divided by the ED triage nurse into five categories according to their medical condition; level 1 - patient requires immediate evaluation and care, level 2 - patient requires evaluation and care within 15 min, level 3 - patient requires evaluation and care within $30 \mathrm{~min}$, level 4 - patient requires evaluation and care within $60 \mathrm{~min}$, and level 5 - patient requires evaluation and care within $120 \mathrm{~min}$ [8-10]. The triage process includes a brief history of the chief complaint and past medical history, obtaining vital signs, assessing pain level, and treatment where applicable. Once triage is completed, the patient is referred for assessment and/or treatment by a physician, or returns to the waiting room. Afterwards, patients can be observed for few hours, can be discharged home, or can be admitted to a pediatric ward. The ED does not include a short-stay unit.

\section{Study outcome measure}

The primary outcome measure for this study was the ED waiting time; the time elapsed from patient's registration at the reception desk until completion of triage process by the triage nurse.

\section{Data collection}

Data were extracted from the hospital's electronic medical records ('Prometheus'). This computerized system is a mandatory working tool for all physicians, nursing staff, social workers, and any ED healthcare personnel. Patient's demographic data, including identification number and ethnicity, are obtained from the parents by the ED clerk and recorded in the system. The following variables were abstracted: ED waiting time, demographics (age, gender), time of arrival (07:00-15:00, 15:0023:00, 23:00-07:00), triage category (1-5), and ethnicity category (Arab, Jew). For each patient, triage nurse ethnicity was also extracted to examine the effect of nurse- patient ethnic concordance on waiting time. Triage nurse ethnicity was identified by name.

The study was approved by the institutional review board.

\section{Statistical analysis}

Data were analyzed with SPSS 21 version (SPSS-IBM, Chicago, IL).

Univariate and multivariate analyses were used to assess the strength of association between ethnicity category (Jew, Arab) and ED waiting time (the dependent variable). The following variables were tested as possible confounders: triage category, diagnosis (medical, trauma), age ( $\leq 1$ year, $>1$ year), gender (male, female), time of arrival category (07:00-15:00, 15:00-23:00, 23:00-07:00). The normality of the quantitative parameter (waiting time) was tested by the Kolmogorov-Smirnov test and this variable was not normally distributed. Waiting times were positively skewed and were normalized with a natural logarithm transformation before analysis. We estimated the predicted probabilities by means of change in waiting

Table 1 Bivariate analysis of ED waiting times ( $n=82,883)$

\begin{tabular}{|c|c|}
\hline Predictors of ED waiting time ${ }^{a}$ & $\begin{array}{l}\text { Unadjusted waiting time in minutes } \\
(95 \% \mathrm{Cl})\end{array}$ \\
\hline \multicolumn{2}{|l|}{ Age } \\
\hline $\begin{array}{l}\leq 1 \text { year } \\
>1 \text { year }\end{array}$ & $\begin{array}{l}37.94[37.92 \text { to } 37.96] \\
38.25[37.98 \text { to } 38.45]\end{array}$ \\
\hline \multicolumn{2}{|l|}{ Gender } \\
\hline $\begin{array}{l}\text { Male } \\
\text { Female }\end{array}$ & $\begin{array}{l}37.48[37.25 \text { to } 37.68] \\
38.10[37.85 \text { to } 38.26]\end{array}$ \\
\hline \multicolumn{2}{|l|}{ Ethnicity } \\
\hline $\begin{array}{l}\text { Jewish } \\
\text { Arab }\end{array}$ & $\begin{array}{l}38.31[37.91 \text { to } 38.54] \\
37.95[37.62 \text { to } 38.24]\end{array}$ \\
\hline \multicolumn{2}{|l|}{ Diagnosis } \\
\hline $\begin{array}{l}\text { Trauma } \\
\text { Medical }\end{array}$ & $\begin{array}{l}38.14[37.92 \text { to } 38.37] \\
37.87[37.65 \text { to } 38.25]\end{array}$ \\
\hline \multicolumn{2}{|l|}{ 24-h time of arrival } \\
\hline $\begin{array}{l}07: 00-15: 00 \\
15: 00-23: 00 \\
23: 00-07: 00\end{array}$ & $\begin{array}{l}40.20[39.87 \text { to } 40.52] \\
39.84[39.53 \text { to } 40.16] \\
37.23[36.45 \text { to } 39.68]\end{array}$ \\
\hline \multicolumn{2}{|l|}{ Triage level $^{\mathrm{b}}$} \\
\hline $\begin{array}{l}1 \\
2 \\
3 \\
4 \\
5\end{array}$ & $\begin{array}{l}28.31[26.86 \text { to } 29.73] \\
29.72[28.99 \text { to } 30.38] \\
33.86[33.31 \text { to } 34.37] \\
35.30[34.74 \text { to } 35.83] \\
42.45[40.23 \text { to } 44.69]\end{array}$ \\
\hline \multicolumn{2}{|c|}{$\begin{array}{l}\text { ED Emergency Department, } C l \text { Confidence Interval } \\
{ }^{a} E D \text { waiting time = Time from patient registration at the recer } \\
\text { completion of triage process } \\
\text { bPediatric Canadian Triage Acuity Scale: } \\
\text { Level } 1 \text { - patient requires immediate evaluation and care; } \\
\text { Level } 2 \text { - patient requires evaluation and care within } 15 \mathrm{~min} \text {; } \\
\text { Level } 3 \text { - patient requires evaluation and care within } 30 \mathrm{~min} \text {; } \\
\text { Level } 4 \text { - patient requires evaluation and care within } 60 \mathrm{~min} \text {; } \\
\text { Level } 5 \text { - patient requires evaluation and care within } 120 \mathrm{~min}\end{array}$} \\
\hline
\end{tabular}


time. The non-parametric Mann-Whitney test was used to test for a difference in waiting times between the two ethnic groups.

\section{Results}

During the 5-year study period, 83,609 patients were admitted to the pediatric ED. Missing data was found in 726 patients. Full data were available in 82,883 patients, 55,497 (67.0\%) Jews and 27,386 (33.0\%) Arabs. 56,175 (67.8\%) patients had medical emergencies and 26,708 (32.2\%) patients had trauma-related emergencies. Male/ female ratio was $57.7 / 42.3$.

Jews and Arabs had a median waiting time of $38 \mathrm{~min}$, interquartile range [IQR] 22-63 $\mathrm{min}$, and $38 \mathrm{~min}, \mathrm{IQR}$ 21-61 min, respectively.

Table 1 presents a bivariate analysis of waiting times in minutes. Table 2 presents a multivariate regression model for the change in waiting time in the study population $(n=82,883)$. Ethnicity did not influence ED waiting times. Factors that most influenced shorter waiting times were triage category 1 (change in waiting time: $-25.5 \%$; $95 \%$ CI: -29.3 to -21.7 ), or triage category 2 (change in waiting time: $-21.8 \%$; 95\% CI: -23.7 to -20.05 ). Factors that most influenced longer wait times were patient arrival during the morning (change in waiting time: 5.45\%; 95\% CI: 4.59 to 6.31), or during the evening (change in waiting time: 4.46\%; 95\% CI: 3.62 to 5.29 ).

\section{Waiting times and nurse-patient ethnic concordance}

Overall, 81,252 (98\%) patients were triaged by 12 Jewish nurses and five Arab nurses. Triage nurse identity was missing in 1631 (2\%) patients. A total of 57,698 (71\%) patients were triaged by Jewish nurses and 23,544 (29\%) were triaged by Arab nurses (Table 3).

\section{Discussion}

Previous studies have shown that ED delay can be associated with adverse outcomes in children. Bonadio et al. reported that in children, increasing the period of time from ED presentation to appendectomy was associated with an elevated risk of developing appendix perforation. Depinet et al. reported an association between ED crowding and delays in the reassessment of critically abnormal vital signs in children $[1,2]$. Kennebeck et al.

Table 2 Predictors of waiting time in the $\mathrm{ED}(n=82,883)$

\begin{tabular}{|c|c|c|c|c|}
\hline Predictors of ED waiting time ${ }^{a}$ & $\begin{array}{l}\text { Unadjusted percentage of change } \\
\text { in waiting time }(95 \% \mathrm{Cl})\end{array}$ & $P$ value & $\begin{array}{l}\text { Adjusted percentage of change } \\
\text { in waiting time }(95 \% \mathrm{Cl})\end{array}$ & $P$ value \\
\hline \multicolumn{5}{|l|}{ Age } \\
\hline $\begin{array}{l}\leq 1 \text { year } \\
>1 \text { year }\end{array}$ & $\begin{array}{l}-0.15[-0.20 \text { to }-0.11] \\
\text { Reference }\end{array}$ & $<0.001$ & $\begin{array}{l}-0 \cdot 18[-0.23 \text { to }-0.13] \\
\text { Reference }\end{array}$ & $<0.001$ \\
\hline \multicolumn{5}{|l|}{ Gender } \\
\hline $\begin{array}{l}\text { Male } \\
\text { Female }\end{array}$ & $\begin{array}{l}-1.38[-1.96 \text { to }-0 \cdot 82] \\
\text { Reference }\end{array}$ & 0.12 & $\begin{array}{l}-1.25[-1.79 \text { to }-0.65] \\
\text { Reference }\end{array}$ & 0.25 \\
\hline \multicolumn{5}{|l|}{ Ethnicity } \\
\hline $\begin{array}{l}\text { Jewish } \\
\text { Arab }\end{array}$ & $\begin{array}{l}0.83[-0.23 \text { to } 1.43] \\
\text { Reference }\end{array}$ & 0.46 & $\begin{array}{l}0.28[-0.32 \text { to } 0.87] \\
\text { Reference }\end{array}$ & 0.36 \\
\hline \multicolumn{5}{|l|}{ Diagnosis } \\
\hline $\begin{array}{l}\text { Trauma } \\
\text { Medical }\end{array}$ & $\begin{array}{l}0.39[-0.21 \text { to } 0.99] \\
\text { Reference }\end{array}$ & 0.20 & $\begin{array}{l}0.02[-0.51 \text { to } 0.73] \\
\text { Reference }\end{array}$ & 0.68 \\
\hline \multicolumn{5}{|l|}{ 24-h time of arrival } \\
\hline $\begin{array}{l}07: 00-15: 00 \\
15: 00-23: 00 \\
23: 00-07: 00\end{array}$ & $\begin{array}{l}5.79[4.93 \text { to } 6.65] \\
4.86[4.03 \text { to } 5.69] \\
\text { Reference }\end{array}$ & $<0.001$ & $\begin{array}{l}5.45[4.59 \text { to } 6.31] \\
4.46[3.62 \text { to } 5.29] \\
\text { Reference }\end{array}$ & $<0.001$ \\
\hline \multicolumn{5}{|l|}{ Triage level $^{\mathrm{b}}$} \\
\hline $\begin{array}{l}1 \\
2 \\
3 \\
4 \\
5\end{array}$ & $\begin{array}{l}-25.5[-29.3 \text { to }-21.7] \\
-21.8[-23.7 \text { to }-20.05] \\
-10.9[-12.34 \text { to }-9.54] \\
-7.1[-8.57 \text { to }-5.71] \\
\text { Reference }\end{array}$ & $<0.001$ & $\begin{array}{l}-25.5[-29.03 \text { to }-21.5] \\
-21.5[-23.3 \text { to }-19.7] \\
-10 \cdot 8[-12.22 \text { to }-9.41] \\
-6.9[-8.42 \text { to }-5.55] \\
\text { Reference }\end{array}$ & $<0.001$ \\
\hline
\end{tabular}

Notes

ED Emergency Department, $\mathrm{Cl}$ Confidence Interval

${ }^{\mathrm{a}} \mathrm{ED}$ waiting time $=$ Time from patient registration at the reception desk until completion of triage process

${ }^{\mathrm{b}}$ Pediatric Canadian Triage Acuity Scale:

Level 1- patient requires immediate evaluation and care;

Level 2 - patient requires evaluation and care within $15 \mathrm{~min}$;

Level 3 - patient requires evaluation and care within $30 \mathrm{~min}$;

Level 4 - patient requires evaluation and care within $60 \mathrm{~min}$;

Level 5 - patient requires evaluation and care within $120 \mathrm{~min}$ 
Table 3 Nurse-patient ethnic concordance. Data are waiting times, median (interquartile range), minutes

\begin{tabular}{lll}
\hline & Jewish nurse & Arab nurse \\
\hline Jewish patient & $38(22-64)$ & $38(22-60)$ \\
Arab patient & $38(22-67)$ & $38(24-67)$ \\
\hline
\end{tabular}

showed that crowding and ED delay were associated with delays in the receipt of antibiotics for febrile neonates [11].

In our large cohort, a multivariate regression analysis showed that ED waiting time was not influenced by ethnicity, and that the two ethnic groups had a similar median waiting time of $38 \mathrm{~min}$. These findings suggest that ethnicity did not play a role in determining waiting time in this ED. Our findings differ from some United States studies in which ethnic/race disparity in ED waiting times was reported in adult and pediatric EDs [3, 4]. These studies found significant differences in ED waiting times between various ethnic groups, including non-Hispanic whites, non-Hispanic blacks, and Hispanic whites. Potential explanations for this phenomenon were language barrier, discrimination and sociocultural factors. Provider-related variables, such as prejudice and stereotyping, were also suggested as possible causes [3, 4, 12, 13]. In Israel, due to the National Health Insurance Law which came into effect in 1995, a patient admitted to the ED of a public hospital is covered by universal health insurance and is not required to pay for any treatment [14]. The fact that health care is covered equally for Jews and Arabs may have contributed to the finding of similar ED waiting times between the two ethnic groups.

Our study is the first to assess ED waiting times in a bi-ethnic population of Jews and Arabs. An important finding of our study is that ethnic discordance between nurses and patients did not yield longer waiting times (Table 3). This finding suggests that triage nurses in this department do not discriminate between ethnicities. A possible explanation could be the fact that triage nurses in this department undergo regular in-hospital triage training, to ensure that all children are assessed and prioritized for care based on clinical need. Nurse training includes educational sessions that contain simultaneous multiple patient simulations, human patient simulations, and online learning courses throughout the year $[15,16]$.

Our study has limitations inherent in a retrospective study, including dependence on the quality of the database. We believe that this factor had minimal impact because of the high quality of the hospital electronic registry. This computerized system consists of in-house Oracle based software (Prometheus) which was specially designed for storing data in real time. A second limitation is that this study is a single center study; therefore, conclusions may not apply to other EDs in Israel.
In conclusion, we found that waiting times were not influenced by ethnicity, were similar for both ethnic groups, and that triage nurses did not discriminate between the two ethnic groups. These data suggest that there was no ethnic disparity with regard to ED waiting time.

Our data provide evidence for equity in emergency care between Jews and Arabs in this ED. Further research on a national level is needed to clarify if the findings of this study apply to other EDs in Israel.

\begin{abstract}
Abbreviations
ED: Emergency Department

\section{Funding}

For all four authors, there are no potential conflicts of interest, real or perceived in the study design, the collection, analysis, and interpretation of data, the writing of this article, and the decision to submit the article for publication. No honorarium, grant, or other form of payment was given to anyone to produce the manuscript.
\end{abstract}

\section{Financial disclosure}

None declared for all four authors.

\section{Author's contributions}

OF designed the study and the analysis plan, Acquisition of the data. Analyzed and interpreted the data, and critically revised the manuscript for important intellectual content. RA acquisition of the data. Analyzed and interpreted the data, and critically revised the manuscript for important intellectual content. RL carried out the statistical analysis, Analyzed and interpreted the data, and critically revised the manuscript for important intellectual content. IS designed the study and the analysis plan, drafted the manuscript, and analyzed and interpreted the data. All authors read and approved the final manuscript.

Ethics approval and consent to participate

The study was approved by the institutional review board.

\section{Competing interests}

The authors declare that they have no competing interests.

\section{Publisher's Note}

Springer Nature remains neutral with regard to jurisdictional claims in published maps and institutional affiliations.

\section{Author details}

${ }^{1}$ Pediatric Emergency Department, Rambam Health Care Campus, Haifa, Israel. ${ }^{2}$ Rappaport Faculty of Medicine, Technion-Israel Institute of

Technology, Haifa, Israel. ${ }^{3}$ Quality of Care Unit, Rambam Health Care Campus, Haifa, Israel. ${ }^{4}$ POB 274, 3080500 Haifa, Israel.

Received: 23 August 2017 Accepted: 3 November 2017

Published online: 10 November 2017

\section{References}

1. Depinet HE, Iyer SB, Hornung $R$, et al. The effect of emergency department crowding on reassessment of children with critically abnormal vital signs. Acad Emerg Med. 2014;21(10):1116-20.

2. Bonadio W, Brazg J, Telt N, et al. Impact of in-hospital timing to appendectomy on perforation rates in children with appendicitis. J Emerg Med. 2015;49(5):597-604.

3. James CA, Bourgeois FT, Shannon MW. Association of race/ethnicity with emergency department wait times. Pediatrics. 2005;115:e310-5.

4. Park CY, Lee MA, Epstein AJ. Variation in emergency department wait times for children by race/ethnicity and payment source. Health Serv Res. 2009:44:2022-39.

5. Zionit Y, Ben-Arieh A, Berman Z. The State of the Child in Israel: 2016 Annual report (Hebrew). http://fs.knesset.gov.il/20/Committees/20_cs_bg_ 367605.pdf. Last accessed in July 21, 2017.

6. https://www.rambam.org.il/EnglishSite/Pages/default.aspx. Last accessed in October 17, 2017. 
7. Gravel J, Fitzpatrick E, Gouin S, et al. Performance of the Canadian triage and acuity scale for children: a multicenter database study. Ann Emerg Med. 2013;61:27-32.

8. Yates MT, Ishikawa T, Schneeberg A, Brussoni M. Pediatric Canadian Triage and Acuity Scale (PaedsCTAS) as a Measure of Injury Severity. Int I Environ Res Public Health. 2016;13(7). doi:10.3390/ijerph13070659.

9. Gravel J, Gouin S, Goldman RD, Osmond MH, Fitzpatrick E, Boutis K, et al. The Canadian triage and acuity scale for children: a prospective multicenter evaluation. Ann Emerg Med. 2012;60:71-7.

10. Gouin S, Gravel J, Amre DK, Bergeron S. Evaluation of the Paediatric Canadian triage and acuity scale in a pediatric ED. Am J Emerg Med. 2005;23:243-7.

11. Kennebeck SS, Timm NL, Kurowski EM, et al. The association of emergency department crowding and time to antibiotics in febrile neonates. Acad Emerg Med. 2011;18(12):1380-5.

12. Qiao WP, Powell ES, Witte MP, et al. Relationship between racial disparities in ED wait times and illness severity. Am J Emerg Med. 2016;34:10-5.

13. Sonnenfeld N, Pitts SR, Schappert SM, et al. Emergency department volume and racial and ethnic differences in waiting times in the United States. Med Care. 2012;50:335-41.

14. Rosen B, Waitzberg R, Merkur S. Israel: health system review. Health Syst Transit. 2015;17(6):1-212.

15. Horsley TL, Bensfield LA, Sojka S, et al. Multiple-patient simulations: guidelines and examples. Nurse Educ. 2014;39:311-5.

16. Rankin JA, Then KL, Atack L. Can emergency nurses' triage skills be improved by online learning? Results of an experiment. J Emerg Nurs. 2013;39:20-6.

\section{Submit your next manuscript to BioMed Central and we will help you at every step:}

- We accept pre-submission inquiries

- Our selector tool helps you to find the most relevant journal

- We provide round the clock customer support

- Convenient online submission

- Thorough peer review

- Inclusion in PubMed and all major indexing services

- Maximum visibility for your research

Submit your manuscript at www.biomedcentral.com/submit

) Biomed Central 